$$
C_{0 x}=-5+0+145-m
$$

UCis, $=-013: 1$

jEQ5 001000

\title{
AB INITIO CALCULATIONS OF THE OPTICAL PROPE'ITIES OF IONS IN GLASS
}

\author{
Narvin J. Weher
}

\author{
This paper was prepared for submittal to the \\ Journal of Non-Crystalline Solids \\ and \\ the Sumposium on Glass Science \& Technoloqy \\ University of Vienna, Vienna, Austria \\ July 2-6, 1984
}

August 1984

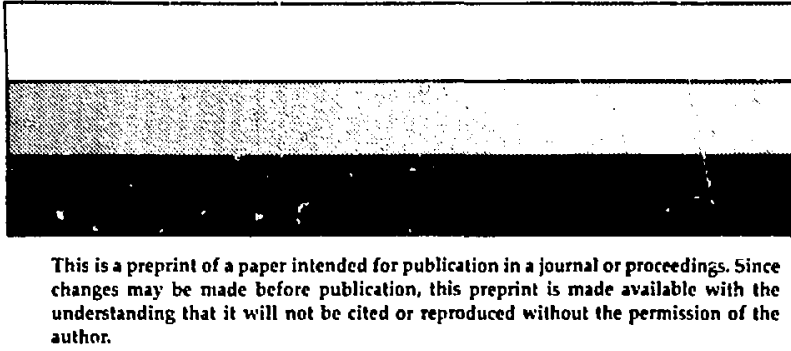
author.

\section{DISCLAIMER}

This repirt was prepared as an account of work sponsored by an agency of the United States Government. Neither the United States Government nor any agency thereof, nor any of their employees, makes any warranty, express or implied, or essumes any legal liability or responsibility for the accuracy, completeness, or usefuldess of any information, apparatus, product, or process disclosed, or represents that its use would not infringe privately owned rights. Reference herein to any specific commercial product, process, or service by trade name, trademark, manufacturer, or otherwise does not necessarily constitute or imply its endorsement, recommendation, or favoring by the United States Government or any agency thereof. The views and opinions of authors exprassod herein do not necessarily state or reflect those of the United Statea Government or any agenty tbetcol. 
AE INITIO CALCULATIONS RF THE OPTICAL PROPERTIES OF IONS IN GLASS

\author{
Marvin J. Heber \\ Lawrence Livermore National Laboratory \\ University of Californie \\ Livermore, CA 94550 U.S.A.
}

\title{
Introduction
}

There is continued interest in the optical properties of ions in insulating glasses for various absorption, luminescence and quantum electronic applications.' Examples include selective absorption filters, scintillatcrs and phosphors, photochromic glasses, lasers, and Faraday rotators. Material a with the desired optical properties for such applications have usually been found empirically - guided by knowledge of properties of related materials - or serendipitously. With time, simple cook and look approaches have evolved into giving the situation the penetrating lopk and coming up with the inspired guess. The question arises whether we are approaching the time now, or in the next twenty years, when reliable computational procedures can be developed to predict glass compositions having specific optical properties without this traditional reliance on empiricism.

The dependence of many physical properties on glass composition can je parameterized and predicted using additivity relations and parameters derived experimentally. This apprcich 
has been known and used for many years.a The quality of the predictions and the range of their applicability depend upon the experimental data base and the type of teras and number of parameters in the expression for the property of interest.

Computational procedures which require extensive experimental data as input are not the type we want to consider here. Instead we address the much more difficult task of predicting optical properties of ions in glass from first principles given only the physics of the constituent atoms. Such an ab initio method is potentially the most powerful and flexible predictive technique. A key element in this approach is the availability of computers sufficient for large-scale quantum mechanical calculations and simulations.

Dependirg upon the application, the active ion may be a transition metal, rare earth, or post transition group elemert, thus vastly differing bonding and electronic structures must te treated. Spectroscopic properties of the dopant icn of interest include the electronic energy levels, absorption and emission spcctra, cross sections, and radiative and nonradiative transition probabilities. The effects of vibrations and temperature on these properties are also of interest. Since aost dopant ions enter the olass network as modifier cations, if we can treat them successfully, then calculations of electronic structure should be extentable to network forming and modifying cations and anjons.

Hence the dependence of the fundamental absorption edge and refractzve index of the host glass on composition and temperature should also be predictabler. 


\begin{abstract}
An indication of the prospects for developing ab injtio computational procedures can be gleaned from an examination of the encouraging, albeit gradual, probress made in understanding the properties of dopant ions in crystals. This is justified because, as Zachariasen roted many years ago, 3 olass is merejy a crystal with an infinitely large unit cell and contajining an infinite number of atoms.
\end{abstract}

\title{
Optical Spectra in Crystals
}

After several decades of effort, accurate ab initio characterizations of the electronic structur: of impurities in crystals are still elusive. Impurity levels are frequently well separated from those of the host crystal and thus $c$ an be treated as localized. Calculations generally fall into two categories: (1) prediction of wavefunctions for an ion in a given local peometry and (2) determination of the optimum geometry for a given impurjty. Reference 4 contains a good survey of the state of the art in both of these areas.

Crystal fieid and ligand field theories have achieved some notable successes in calculating electronic energy levels, but these approaches involve parameterizing the field using a minimum number of terms consistent with the local symmetry. For most ion-host systens, attempts to predict urystal field paraneters from first principles using electrostatic models is a well documented failure. Models intermediate between an entirely 
phenomenological treatment and a complete linear-combination-ofatomic-orbitals calculation have been developed; examples of their successes and failures are discussed in Ref.5.

Molecular orbital calculations pr.vide a more rigorous prediction of energy levels of ions in solids. Electronic structures can be examined using a variety of molecular arbital procedures including purely ab initio methods. Since the electron states associated with the impurjty are localized on a few atoms, a small number of atoms may be used to model this region of the crystal in real space. These so-called cluster methods (reviewed in Chapter b of Ref.4) are very versatile. However, a problem associated with all cluster-type models is the treatment of atoms on the surface of the cluster and simulation of the crystal beyond the cluster. Several approximations have been used but definitive experimental confirmation of their approp-iateness is missing.

Cluster molecular orbitals are generally expressed as linear combinations of atomic-orbital-jike basis functions centered on the nuclei. As the number of required basis functions increases, the number of integrals to be evaluated and the amount of computer time reeded escalates rapidly. As a consequence, pseudopotential techni ques have been used. These techniques can be ab initic in form; no parametric functional forms are assumed and no experimental data is needed to construct them. - 
Calculations of electronic properties requires that the atom positions about the impurity ion be specified. Structural simulations of crystals have ranged from simple oxides and alkali halides to complex minerals. " Theoretical calculations involvino minimization of the total energy have made possible the Jeterminations of crystal structure, lattice constants, bulk moduli, and phonon dispersive curves. The methods can be ab initio and depend on pseudopotentials generated knowing only the atomic number of the constituent element5.* When a dopent is introducfed, it constitutes a point defect. Therefore treatment of lattice relayation effects must be included to obtain proper positions of the surrounding atoms or those within a cluster. Structural simulations must also account for instabilities against symmetry or charge-state changes and the effect of electronic excitatic.. since the structure of the neighboring ions may differ when the ion is in an excited state.

The reliability of calculations of static features, which depend on short-range order, and dynamic features, which depend on intermediate-range order, involve a delicate balance of energies and are limited by the quality of the interaction potentials used in the simulations.

Metal impurities in crystals can be treated using quantum mechanical methods developed for treating large molecules. Large basic set apen shell hartree-Fock calculations are currently being carried out for clusters of over 30 atoms.? Computer codes are being expanded to include electron correlation, spin-orbit coupling, and configuration interactions. These powerful, nodern theoretical methods are very promising but have yet to address all of the many issues mentioned above. 


\section{Optical_Seectra in Glass}

Al 1 atoms in a glass are structurally inequivalent. Therefore in the present context, glasses differ from crystals principally in that rather than having one or a few sites of specific geomenty, there is a distribution of different local environments for the optically active ions. The resulting site-to-site variations ir. electrostatic, spin-orbit, and crystal fjeld interactions produce a range of energy level separations and transition probabilities. These are revealed spectroscopically by inhomogeneously broadened linewidths and nonexponential excited-state decays. In glass lasers, differences in the microscopic structure at the lasing ion sites lead to spectral and polarization hole burning effects.-

Most spectroscopies used to investigate ions in glasses such as nuclear and electron spin resonance, Raman, alld optical techniques yield information about the entire ensemble of physically different sites; details about individual sites are not provided. Laser spectroscopy, in contrast, can be used to selectively excite and study specific subsets of ions - those in sites having energy levels in resonance with the laser wavelength. (These subsets may still contain large numbers of sites.) Techniques such as laser-induced optical site selection spectroscopy and fluorescence 1 ine narrowing 20 and photophysical and photochemical hole burning 22 provide unique capabilities to probe impurity sites with extremely fine spectral and temporal resolution. The degree of site selectivity depends on the ratio 
of the natural or homogeneous optical linewidth tp the inhomogeneous 1 inewidth. Experiments using rare-earth ions and transitions having homogeneous 1 inewidths very much smaller than the inhomogeneous linewidth in olass clearly demonstrate the existence of large numbers of physically different sites. 10

Al though site-selective laser spectroscopy provides unique information about ions in glass, both the local structure and resultant fields must be known to predict the opti al spectra. The comments made earlier about the prospects for ab initio calculations of electronic properties of ions in erystals are again apropos fur glasses. Calculations for glass, however, are hampered further by our lack of knowledge of the local geametry, its variation from site to site, and its dependence on chemical composition.

\section{Simulation of Gless Structure}

Molecular dynamics, which has been used extensively in stucies of liquids, has also been used to simulate local atomic arrangements about sodifier cation sitesin simple and multicomponent glasses. $2=$ The simulation begins by specifying the initial positions of a group of ions, their velocity distribution characteristic of a specific temperature, and the interatomic potentials. Newton's equations of motion are then solved numericaliy to find new positions and velocities at a later time. The time steps are typically in the order of fentoseconds ( less than a vibrational 
periods. About $10^{3}-10^{*}$ steps are used to generate an equilibrium fluid. To simulate a glass, one or more structural configurations of the fluid are quenched in a series of sten reductions of the temperature. The low temperature configuration may be further relaxed to a local energy minimum. 23 The collection of structures resulting from many such simulations is assumed to represent the range of local environments present in the glass. Both radical and angular information sbout pairs or larger groups of ions can be calculated from the simulated structures.

\section{Computer simulations of glass have several limitations.} First, because of cost the total time of the simulation is typically very short, less than 1 nanosecond. The cooling rates are therefore very much faster than those of laboratory prepared glasses and the simulated structures are expected to be more disordered.14 Second, the interaction potentials used thus far have been spherically symmetric consisting of Coulomb and exponential repulsion terms. The strength of these interactions are not known apriori and are adjusted based upon experimental data or estimated crystal properties. Finally, the size of the systems that can reasonably be treated with present-day computers is about $10^{3}$ particles. To reduce surface effects, periodic boundary conditions are imposed. While this may be adequate for treating localized impurities, larger systems are needed to treat extented defects or those occurring with low probability. 
Computer simulations using molecular dyamics methods have: other applications. Since they also provide kinetic information, they can be used to investigate properties such as vibrational modes and their effects on optical spectra. Vibrational spectra have been calculated either by direct diagonajization of the dynamical matrix for the 9 lass or from autocorrelation functions computed directly from the simulations. $2:$ Quench echoes, which occur in computer models of glassy solids, offer a further technique for studying dynamic behavior.to Striking differencer in the low-temperature properties of crystalline and amorphous selids have been attributed to low energy excitations, known as two-level systems. 26 The microscopic nature of these exicitations and how they are related to various physical properties of glass are unknown, but could be investigated using large-scale computer simulation techni ques.

Validation of the simulated structures of glass is 1 imited because no measurement is capable of specifying the threedimensional structure uniquely. Satisfactory agreement has been found between predicted average coordination numbers, neighbor distances, and bond angles and results of $x-r$ ay and neutron diffraction studies.: 2 The structure about a specific ion and Partial distribution functions, which are of interest here, can be explared via NMR, EXAFS, neutron scattering with isotopically enriched samples, and $x-r a y$ scattering using synchrotron radiation and anamolous dispersion effects.27 Preliminary investigations show general agreement with the simulated iocal structures but 
mare detailed comparisons with experiment are needed. Predicted bond angle distributions do not appear to be reliable using only radially dependent forces. 10

Optical spectra have al so been compared with computer simulations using simple electrostatic models of the crystal field . 17-20 Although qualitative agreements are obtained, accurate calculations and simulations of both the local structure and electronic energy levels are required to interpret optical spectra in glass, features that have been treated with only limited success to date in crystals.

\section{Conclusions}

Is there hope that we will ever be capable of simulating atomic structures comparable to those actually oceurring in laboritory and production glasses and of e: Jculating the electronic properties of both an impurity ion and the host glass fron first principles? A unified treatment of structure and optical properties of the host and dopant ion is in the offing. It is therefore not a question of possibility but rathar one of probability within a given time span. Large increases in computing power - greater speed and larger storage capacity - and faster algorithms will undoubtedly appear and should make possible the simulation or systems of sufficient size to include mos: excitacions and defect structures of interest. 
The answer to the above question wijl continue to be guided by progress made in treating crystalline aterials and by the success of varjous potential modus in predi"ting equijibrium positions of ions, charge states, opnamic preperties, and electronic structures is the host and impirity ions. I believe it is probable that in twenty years we will have reliable ororidures for predicting optical properties of ions in erystals.

The devejopment of corresponding procedures for predicting the properties of complex, multicomponent glasses wittin two decades is a herculean tasl:. I am Jess sanguine about the probability of achieving this goal brfare Professor krejeste looth birthday. But aven if the ab initio methade are not totaliy reliable in maling quantitative precictions, they whould still be ugeful. Legs heroic predictions of the general trends of properties with compusition should be poseible and sho:ld offer valuable guidance in compoeitional studics.

An important question to be aslies is the cost effectiveness of computer simulations in comparison to laboratory exporimerits.

K. (5. Wilson noted recently that "Computer simulation, wher" feasible, is usually the least expensive and most -apid mothod available for prototyping and optimization of new products and processes He added "It takes many years of practical experience with large scale computing to be able to make sensibje decisions or provide sound advice on simulation matters". 22 The remainder of this Ini:lenium would seem to be the minimum expectation of the time necessary to reach this stage in the simulation of optical properties of jons in glass. 
More detailed and critical experimental tests of computer simulations invelving both evolutionary and revolutionary devel opments are certain to occur in the future. Angle-resolved photoelectron spectroscopy in the VUV and x-ray regions usino synchrotron radiation and inverse photoemission techni ques ore greatly enhancino experimantal studies of electronic structures of complicated solids. Atomir-resolution electron microscopy and narometer-scale electron microdiffraction should yield important structural information about amorphous materials. Lasor 5. sctroscopy with spectral resolution measured in Hertz and temporal resolution measured in femteseconds is possible todar. Combined with multiple excitation schemes, unique site specific information should be obtainable. Optical dephesing studiec using photon echoes have recently been used to investigate two-level systems and tunneling modes in olass. 22 The above techniques and other as yet unexpected techniques will be the final arbiters in ustublishing the validity of large-scale computer simulations for screening and prodicting new ol ass compositions.

\section{Acknowledoaents}

This work was performed under the auspices of the Division of Materials Sciences, Office of Basic Energy Sciences, of the U.S. Department of Energy by the Lawrence Livermore National Laboratory unider contract number W-7405-ENG-48. The hospitality of the National Bureau of Standards where I was a guest worker during the preparation of thie manuscript is gratefully acknowledged. 


\section{References}

1. H. Rawson, Properties and Applications of Glass relnevier. Amsterdan, 1980).

2. G. Morey, Properties of Glass (Van Nostratid Reinhold, New York, 1954,

3. W. H. 2 achariasen, J. Am. Chem. Sor. 554, 3841 (193.2).

4. Computer Simulation of Solids, edited by C. R. A. Catlow and W. C. Mackrodt (Springer, Berlin, 1982).

5. M. Faucher and D. Garcia, J. Less-Cammon Metals 93,31 (1983).

7. 2. N. W. Winter and R. M. Pitzer, "Modern Theoretical Methods for the Study of Impurities in Crystals" (in press).

6. \%o See 5. Froyen and M. Cohen, Phys. Fev. $\mathrm{B}$. 3770 (1984) and references cited therein.

B. D. W. HaJ 2, R. Haas, W. F. Kirupke, and M. J. Weber, IEEE J. Duantum Electron. OE-19, 1704 (1983).

9. J. Wong and C. A. Angell, Glass Structure by Spectroscapy (Dekker, New York. 1976).

10. Laser Spectroscopy of Solide. edited by $W$. M. Yen and P. M. Selzer (Springer, Berlin, 1982$).$

11.0. Friedrich and D. Haarer, Angew. Cher., Int. Ed. Engl. 23, 113 $(1984)$.

12.T. F. Soules, J. Non-Cryst. Solids 49, 29 (1482).

13.5. A. Brawer, J. Chem. Phys. 79, 4539 (1983).

14.L. V. Woodcack, C. A. Angell, and P. Cheeseman, J. Chem. Phys. 65, $1565(1976)$.

15.5. R. Nagel, G. S. Grest, and A. Rahman, Physics Today, D.24 (October 1983). 
$-14-$

16. Amorphous Solids: Low-Temperature Properties, edited by $W$. $A$. Phillips (Springer, Berlin, 1981).

17. M. J. Weber and 5. A: Brawer, J. Phys, (Paris) 43, Celloq. C9, 291 (1982).

18. W. J. Deld, R. V. Mulkern, P. J. Bray. M. J. Weber and S. A. Brawer. Phys. Rev. B (in press).

19. 5. A. Brawer and M. J. Webar, Phys. Rev. Lett._45, 460 (1980). 20. M. J. Weber and S. A. Brawer, J. Non-Cryst. Solids 5ㄹ, 321

21. K. G. Wilson, Commun. ACM 27, 295 (1984).

22. J. Hegarty, M. M. Broer, B. Golding, J. B. Simpson, and J. B. Macchesney, Phys. Rev. Lett..51, 2033 (1983). 


\section{DISCLAIMER}

This document was prepared as an account of work sponsored by an agency of the United States Government. Neither the United States Government nor any agency thereof, nor any of their employees makes any warranty, expressed or implied. or assumes any leqal liability or responsibility for the accuracy, completeness, cr usefulness of any information, apparatus, product, or process disclosed, or represents that its use would not infringe privately owned rights. Reference herein to any specific comnercial product, process, or service by trade name, trademark, nanufacturer, or otherwise, does not necessarily constitute or imp2y its endorsement, recommendation, or favoring sy the United states Government or any agency thereof. The views and opinions of authors expressed herein do not necessarily state or reflect those of the United States Government or any agency thereof. 